\title{
ANTROPOMETRI WANITA PRA HAMIL DAN PENGARUHNYA PADA PERTAMBAHAN BERAT BADAN SELAMA KEHAMILAN DI KECAMATAN BOGOR TENGAH, KOTA BOGOR
}

\author{
Anies Irawati, Andi Susilowati \\ Peneliti pada Pusat Teknologi Intervensi Kesehatan Masyarakat \\ irawati.anies@yahoo.com
}

\begin{abstract}
ABSTRAK
Kehidupan janin dalam kandungan merupakan tahap peratama 1000 hari kehidupan yang menentukan kualitas manusia dimasa depan. Pertambahan berat badan ibu selama kehamilan merupakan indikator status gizi ibu hamil dan janin, yang tergantung pada status gizi ibu sebelum hamil. Ukuran antropometri ibu pra mil merupakan indikator yang mudah dan valid untuk prediksi status gizi ibu hamil. Tujuan penelitian ini adalah menilai perbedaan pertambahan berat badan ibu selama kehamilan menurut ukuran antropometri berisiko (tinggi badan $<150 \mathrm{~cm}$, berat badan sebelum hamil $<45 \mathrm{~kg}$, indeks massa tubuh sebelum hamil $<18,5 \mathrm{~kg} / \mathrm{m}^{2}$ dan lingkar lengan atas $<23,5 \mathrm{~cm}$ ). Penelitian kohor prospektif dilakukan pada 401 ibu sejak sebelum ibu hamil sampai anak dilahirkan dan berumur sedikitnya 23 bulan di Kecamatan Bogor Tengah, Kota Bogor yang dilakukan sejak tahun 2012 sampai sekarang. Berat badan dan lingkar lengan atas ibu di ukur setiap bulan, dan tinggi badan di ukur ketika responden dinyatakan hamil oleh bidan. Perbedaan pertambahan berat badan menurut ukuran antropometri berisiko dianalisis menggunakan uji T. Hasil menunjukkan bahwapertambahan berat badan ibu selama kehamilan lebih rendah secara bermakna pada ibu dengan ukuran antropometri berisiko (berat badan sebelum hamil $<45$ $\mathrm{kg}$, tinggi badan $<150 \mathrm{~cm}$, IMT sebelum hamil $<18,5 \mathrm{~kg} / \mathrm{m}^{2}$, LiLA $<23,5 \mathrm{~cm}$ ). Selisih terbesar adalah pada ibu dengan berat badan sebelum hamil $<45 \mathrm{~kg}$ (3,5 kg dari standar IOM 2009). Dapat disimpulkan bahwa berat badan ibu sebelum hamil merupakan indikator untuk pertambahan berat badan ibu selama kehamilan. Disarankan pada ibu yang memulai kehamilan dengan berat badan $<45 \mathrm{~kg}$ perlu pemantauan berkala lebih ketat agar pertambahan berat badan selama kehamilan sesuai anjuran dapat terpenuhi.
\end{abstract}

Kata kunci: antropometri, berat badan, ibu hamil

\section{ABSTRACT}

\section{THE MEASUREMENT OF ANTROPOMETRY IN PREGNANT WOMEN AND ITS IMPACT TO THE INCREASE OF BODY WEIGHT DURING PREGNANCY IN CENTRAL BOGOR SUBDISTRICT, BOGOR CITY}

Maternal anthropometry measurement is a valid indicator for predicting pregnancy weight gain. The objective of the study is to evaluate the difference in weight gain during pregnancy according to maternal anthropometric measurement Prospective cohort study was applied tof 401 pregnant women from pre pregnancy until giving birth in the District Central Bogor, Bogor City since 2012 until now. Weight and mid arm circumference measured every month, and the height is measured one time. The difference in weight gain according maternal anthropometry measurement analyzed using T-test. The results showed that maternal weight gain during pregnancy was significantly lower in women with pre pregnancy body weight $<45 \mathrm{~kg}$, height $<150 \mathrm{~cm}$, BMI before pregnancy $<18.5 \mathrm{~kg} / \mathrm{m}^{2}$, MUAC $<23.5 \mathrm{~cm}$. In conclusion, maternal antropometry measurement before pregnancy is an indicator of maternal weight gain during pregnancy. It is suggested that Women who start pregnancy with anthropometry measurement less than $45 \mathrm{~kg}$ need regular monitoring more frequent in order to achieve weight gain as recommended.

Keywords: anthropometry, body weight, pregnancy 


\section{PENDAHULUAN}

S ecara global, Indonesia termasuk satu dari tujuh belas negara yang menghadapi masalah gizi serius. Posisi Indonesia, termasuk di dalam 17 negara dari 117 negara di dunia yang secara bersama-sama mempunyai tiga masalah gizi saat ini, yaitu stunting (pendek dan sangat pendek), wasting (kurus dan gizi buruk) dan overweight (gemuk dan obes) pada balita. $^{1}$ Riskesdas $2013^{2}$ menyebutkan prevalensi anak balita underweight, kurus dan pendek sebanyak 19,6 persen, 12,1 persen dan 37,1 persen, serta prevalensi balita overweight 11,9 persen.

Prevalensi stunting di Indonesia sangat tinggi, sementara kecepatan penurunannya setiap tahunnya lambat/rendah. Indonesia merupakan negara terbesar ke lima yang berkontribusi terhadap besarnya anak balita stunting di dunia, dan termasuk dalam 47 negara dari 122 negara yang mempunyai masalah Stunting dan Anemia WUS bersamasama. ${ }^{1}$ Target the World Health Assembly (WHA) pada tahun 2025, penurunan jumlah stunting pada Balita sebesar 40 persen, penurunan anemia pada WUS 50 persen, penurunan prevalensi bayi berat lahir rendah sebesar 30 persen dan tidak ada kenaikan prevalensi gizi lebih/overweight pada anak anak, ASI eksklusif 0-6 bulan meningkat setidaknya mencapai 50 persen dan menurunkan/ pertahankan anak-anak kurus (childhood wasting) menjadi kurang dari 5 persen. ${ }^{3}$

Stunting adalah masalah kurang gizi kronis yang disebabkan oleh asupan gizi yang kurang dalam waktu lama akibat pemberian makanan yang tidak sesuai dengan kebutuhan gizi. Stunting dapat terjadi mulai masa janin masih dalam kandungan dan baru terlihat saat anak berusia dua tahun. ${ }^{4}$ Beberapa penelitian membuktikan pengaruh status gizi ibu terhadap gangguan pertumbuhan janin dalam kandungan. ${ }^{5}$ Hanya ada dua indikator dari status gizi ibu yang secara konsisten menunjukkan hubungan yang positif dengan berat badan bayi, yaitu berat badan pra-hamil dan pertambahan berat badan selama kehamilan. ${ }^{6}$ Peneliti lain menjelaskan bahwa tinggi badan ibu mempunyai dampak signifikan pada ukuran bayi neonatus. ${ }^{7}$ Berat badan dan tinggi badan rendah berkaitan dengan meningkatkan risiko kematian perinatal, prematur dan SGA (Small for Gestational Age). Estimasi risiko atributable memperlihatkan bahwa kontributor berat rendah terhadap hasil kehamilan rendah lebih besar dari tinggi badan kurang. ${ }^{8}$ Lingkar Lengan Atas (LiLa) rendah juga berkaitan dengan rendahnya outcome kehamilan. ${ }^{9,10}$

Mulai tahun 2012 dilakukan penelitian kohor tumbuh kembang anak yang dimulai sejak janin dalam kandungan dan direncanakan sampai anak berumur 18 tahun. Untuk mendapatkan gambaran keadaan ibu sebelum hamil, setiap tahun dilakukan pengumpulan data dasar pada semua wanita pra hamil yang berumur $15-49$ tahun di lokasi kohor tumbuh kembang anak. Data yang dikumpulkan adalah karakteristik keluarga termasuk kondisi sosial ekonomi, keadaan lingkungan, status kesehatan (termasuk tekanan darah), ukuran antropometri untuk menentukan status gizi, perilaku hidup bersih dan sehat, perilaku merokok, aktifitas dan status anemia.

Pada artikel ini akan dibahas status gizi wanita pra hamil menurut ukuran antropometri untuk memberikan gambaran risiko bila wanita tersebut hamil. Data lainnya akan dipublikasikan secara terpisah.

\section{METODE PENELITIAN}

Penelitian kohor tumbuh kembang anak dilakukan di Kecamatan Bogor Tengah Kota Bogor sejak tahun 2012, sampai saat ini masih berlaanangsung dan direncanakan sedikitnya sampai tahun 2032. Observasi direncanakan sejak wanita pra hamil, hamil sampai anak yang dilahirkan berumur 18 tahun. Data yang di analisis pada artikel ini adalah pada tahap pra hamil sampai melahirkan.

Data dasar penelitian kohor tumbuh kembang anak dilakukan pada semua wanita pra hamil. Populasi adalah semua wanita usia 15 - 49 tahun, dan sampel adalah wanita usia 15 - 49 tahun yang memenuhi kriteria inklusi. Kriteria inklusi adalah wanita pra hamil umur 15-49 tahun yang belum hamil. Jumlah responden sebanyak 2400 wanita pra hamil dari lima kelurahan, yang datanya dikumpulkan dalam tiga tahun berturut-turut pada tahun 2012 (800 wanita pra hamil di Kelurahan Kebon Kalapa dan Ciwaringin) dan tahun 2013 (800 wanita pra hamil di Kelurahan Babakan, Panaragan dan Babakan Pasar). Pada tahun 
2014 jumlah responden sebanyak 819 wanita pra hamil dari 5 (lima kelurahan) tersebut di atas yang pada tahun 2012 dan 2013 belum dikumpulkan datanya, ditambah dengan wanita pra hamil baru (wanita yang pada tahun 2013 berumur 14 tahun dan pada tahun 2014 berumur 15 tahun). Pengumpulan data dasar tersebut dilakukan selama tiga tahun berturutturut disesuaikan perluasan lokasi kohor tumbuh kembang anak. Diantara 2419 wanita pra hamil tersebut, sebanyak 476 ibu dinyatakan hamil dan di follow up sampai melahirkan, dan 401 ibu telah melahirkan. Analisis ini dilakukan pada 401 ibu hamil yang telah melahirkan tersebut sebab data pertambahan berat badan selama kehamilan dapat diketahui.

Data karakteristik (umur dan paritas) wanita pra hamil dan sosial ekonomi keluarga dikumpulkan dengan menggunakan kuesioner terstruktur. Data antropometri yang dikumpulkan adalah berat badan, tinggi badan, dan lingkar lengan atas (LiLA). Berat badan diukur menggunakan timbangan berat badan digital merek AND dengan ketelitian 50 gram. Tinggi badan diukur dengan alat ukur multifungsi dengan ketelitian $0,1 \mathrm{~cm}$. Lingkar lengan atas di ukur menggunakan pita LiLA dari UNICEF. Petugas pengumpul data adalah sarjana gizi dan D3 kebidanan atau keperawatan. Sebelum pengumpulan data dilakukan pelatihan kepada petugas pengumpul data agar mereka mendapat persepsi dan pemahaman yang sama terhadap maksud setiap pertanyaan dan cara mengisi kuesioner. Selain itu dilakukan pelatihan pengukuran berat badan, tinggi badan dan LiLA. Analisis data deskriptif untuk menjelaskan frekuensi distribusi data berat badan, tinggi badan dan lingkar lengan atas. Izin etik penelitian ini diperoleh dari Komisi Etik Badan Penelitian dan Pengembangan Kesehatan (Nomor LB.02.01/5.2/KE.143/2014).

\section{HASIL}

Data umur kepala keluarga, dan pengeluaran rumah tangga per bulan dan status sosial ekonomi keluarga responden disajikan pada Tabel 1 dan 2. Usia kepala keluarga sekitar 40 tahun, yang merupakan usia produktif. Rerata pengeluaran untuk makanan rumah tangga per bulan adalah Rp. 1,5 - Rp 1,9 juta atau rasio terhadap total pengeluaran sekitar 49 - 55 persen. Untuk jumlah anggota rumah tangga sekitar 4 orang per tumah tangga, maka rerata biaya untuk makanan sekitar Rp. 395 - Rp. 473 ribu per kapita per bulan, atau Rp. 13 - Rp. 16 ribu per kapita per hari atau Rp 52 - 64 ribu per kapita per bulan. Total pengeluaran rumah tangga per bulan adalah Rp. 3,3-Rp 3,8 juta.

Tabel 1

Umur Kepala Keluarga, dan Pengeluaran Rumah Tangga Per Bulan di Kecamatan Bogor Tengah, Kota Bogor

\begin{tabular}{|c|c|c|c|c|c|c|}
\hline \multirow[t]{2}{*}{ Karakteristik } & \multicolumn{2}{|c|}{ Tahun $2012^{*}$} & \multicolumn{2}{|c|}{ Tahun $2013^{* *}$} & \multicolumn{2}{|c|}{ Tahun $2014^{\star \star \star}$} \\
\hline & Rerata & Median & Rerata & Median & Rerata & Median \\
\hline Umur Kepala Keluarga (th) & $40,6 \pm 11,6$ & & $40,4 \pm 10,3$ & & $40,8 \pm 10,2$ & \\
\hline \multicolumn{7}{|l|}{$\begin{array}{l}\text { Pengeluaran RT per bulan } \\
\text { (Rpx1000) }\end{array}$} \\
\hline Makanan & $1.581 \pm 807$ & 1.477 & $1.591 \pm 699$ & 1.457 & $1.890 \pm 923$ & 1,724 \\
\hline Bukan Makanan & $2.135 \pm 1.159$ & 1.116 & $1.688 \pm 1.289$ & 1.279 & $1.890 \pm 4.190$ & 1,389 \\
\hline Total & $3.371 \pm 2.375$ & 2.735 & $3.279 \pm 1.700$ & 2.850 & $3.780 \pm 4.447$ & 3,229 \\
\hline
\end{tabular}


Tabel 2

Karakteristik Sosial Ekonomi Keluarga di Kecamatan Bogor Tengah, Kota Bogor

\begin{tabular}{|c|c|c|c|}
\hline \multirow{3}{*}{ Karakteristik } & \multicolumn{3}{|c|}{ Tahun } \\
\hline & $\begin{array}{c}2012 \\
(\mathrm{~N}=800)^{*}\end{array}$ & $\begin{array}{c}2013 \\
(N=800)^{\star *}\end{array}$ & $\begin{array}{c}2014 \\
(N=819)^{\star \star *}\end{array}$ \\
\hline & $\%$ & $\%$ & $\%$ \\
\hline \multicolumn{4}{|l|}{ Anggota Rumah Tangga } \\
\hline$\leq 4$ orang & 60,3 & 63,6 & 58,5 \\
\hline$>4$ orang & 39,7 & 36,4 & 41,5 \\
\hline \multicolumn{4}{|l|}{ Status Kepala Keluarga } \\
\hline Belum kawin & 0,8 & 0,1 & 0,8 \\
\hline Kawin & 85,5 & 99,3 & 91,1 \\
\hline Cerai Hidup & 1,7 & 0,3 & 2,9 \\
\hline Cerai Mati & 12,0 & 0,3 & 5,2 \\
\hline \multicolumn{4}{|l|}{ Pendidikan Kepala Keluarga } \\
\hline Tidak pernah sekolah & 1,7 & 0,4 & 0,1 \\
\hline Tidak Tamat SD & 7,8 & 4,8 & 3,5 \\
\hline SD & 26,7 & 23,2 & 20,2 \\
\hline SLTP & 24,2 & 24,2 & 23,4 \\
\hline SLTA & 33,4 & 42,5 & 48,5 \\
\hline PT & 6,1 & 4,8 & 4,3 \\
\hline \multicolumn{4}{|l|}{ Pendidikan Wanita } \\
\hline Tidak pernah sekolah & 0,6 & 0,4 & 0,2 \\
\hline Tidak tamat SD & 10,6 & 30,6 & 4,8 \\
\hline SD & 30,1 & 20,5 & 20,5 \\
\hline SLTP & 23,1 & 24,8 & 33,0 \\
\hline SLTA & 29,0 & 45,6 & 38,3 \\
\hline PT & 5,3 & 5,2 & 3,2 \\
\hline \multicolumn{4}{|l|}{ Pekerjaan Kepala Keluarga } \\
\hline Tidak Bekerja & 9,2 & 2,4 & 3,2 \\
\hline Sekolah & 0,6 & 0,0 & 0,8 \\
\hline Wanita Rumah Tangga & 6,1 & 4,8 & 3,9 \\
\hline TNI/POLRI/PNS & 3,9 & 5,4 & 2,8 \\
\hline BUMN/Swasta & 17,8 & 37,6 & 28,1 \\
\hline Pedag/Wiraswasta/Jasa & 35,1 & 26,6 & 35,1 \\
\hline Buruh/lainnya & 27,3 & 23,2 & 26,1 \\
\hline \multicolumn{4}{|l|}{ Pekerjaan Isteri } \\
\hline Tidak Bekerja & 5,0 & 0,8 & 3,4 \\
\hline Sekolah & 3,1 & 0,4 & 1,7 \\
\hline Wanita Rumah Tangga & 60,2 & 80,2 & 72,2 \\
\hline TNI/POLRI/PNS & 0,8 & 0,9 & 0,8 \\
\hline BUMN/Swasta/ & 18,9 & 5,9 & 4,8 \\
\hline Pedagang/Wiraswasta/Jasa & 17,8 & 7.9 & 10,8 \\
\hline Buruh/lainnya & 4,7 & 3,9 & 6,3 \\
\hline
\end{tabular}

Data pada Tabel 2 berikut menginformasikan bahwa sekitar 60 persen keluarga responden dengan jumlah anggota rumah tangga $\leq 4$ orang, dan sekitar $90-99$ persen kepala keluarga dengan status kawin. Sebanyak 50 persen kepala keluarga dan 60 persen responden (wanita pra hamil) berpendidikan SLTP ke bawah. Sepertiga 
kepala keluarga bekerja sebagai pegawai (PNS,TNI,BUMN, Swasta) dan sepertiga lainnya bekerja sebagai pedagang, dan kurang dari sepertiga yang bekerja sebagai buruh. Masih ada sekitar 5 persen yang tidak bekerja. Untuk responden (wanita pra hamil), pola sedikit berbeda dengan kepala keluarga, 70 persen responden adalah ibu rumah tangga, dan sekitar 5 persen sebagai buruh. Sebanyak 3 persen yang tidak bekerja dan sekitar 2 persen yang masih sekolah.

Tabel 3

Kondisi Antropometri Wanita Pra Hamil Berisiko di Kecamatan Bogor Tengah, Kota Bogor

\begin{tabular}{|c|c|c|c|}
\hline Karakteristik & Tahun 2012* & Tahun $2013^{* *}$ & Tahun $2014^{* \star \star}$ \\
\hline Umur (tahun) & $28(15-50)$ & $31(14-49)$ & $31(14-54)$ \\
\hline Umur $<20$ th dan $\geq 35$ th $(\%)$ & 15,5 & 34,5 & 33,3 \\
\hline Berat Badan $(\mathrm{kg})$ & $53,9 \pm 10,5$ & $55,7 \pm 10,7$ & $55,7 \pm 11,5$ \\
\hline Berat Badan < $45 \mathrm{~kg}(\%)$ & 18,6 & 15,2 & 19,0 \\
\hline Tinggi Badan (cm) & $151,7 \pm 5,9$ & $151,6 \pm 5,6$ & $151,6 \pm 6,7$ \\
\hline Tinggi Badan < $150 \mathrm{~cm}(\%)$ & 39,8 & 38,2 & 41,4 \\
\hline IMT pra $\left(\mathrm{kg} / \mathrm{m}^{2}\right)$ & $23,6 \pm 4,4$ & $24,3 \pm 4,6$ & $24,2 \pm 4,7$ \\
\hline Kurus $<18,5 \mathrm{~kg} / \mathrm{m}^{2}(\%)$ & 11,6 & 9,4 & 10,0 \\
\hline Lingkar Lengan Atas (cm) & $27.2 \pm 3,7$ & $27,7 \pm 3,5$ & $27,9 \pm 4,2$ \\
\hline Risiko KEK < 23,5 cm (\%) & 16,2 & 10,9 & 15,2 \\
\hline
\end{tabular}

*Kelurahan Kebon Kalapa dan Ciwaringin

**Kelurahan Babakan, Babakan Pasar dan Panaragan

${ }^{* * *}$ Kelurahan Kebon Kalapa, Ciwaringin, Babakan, Babakan Pasar dan Panaragan

$\mathrm{kg}$

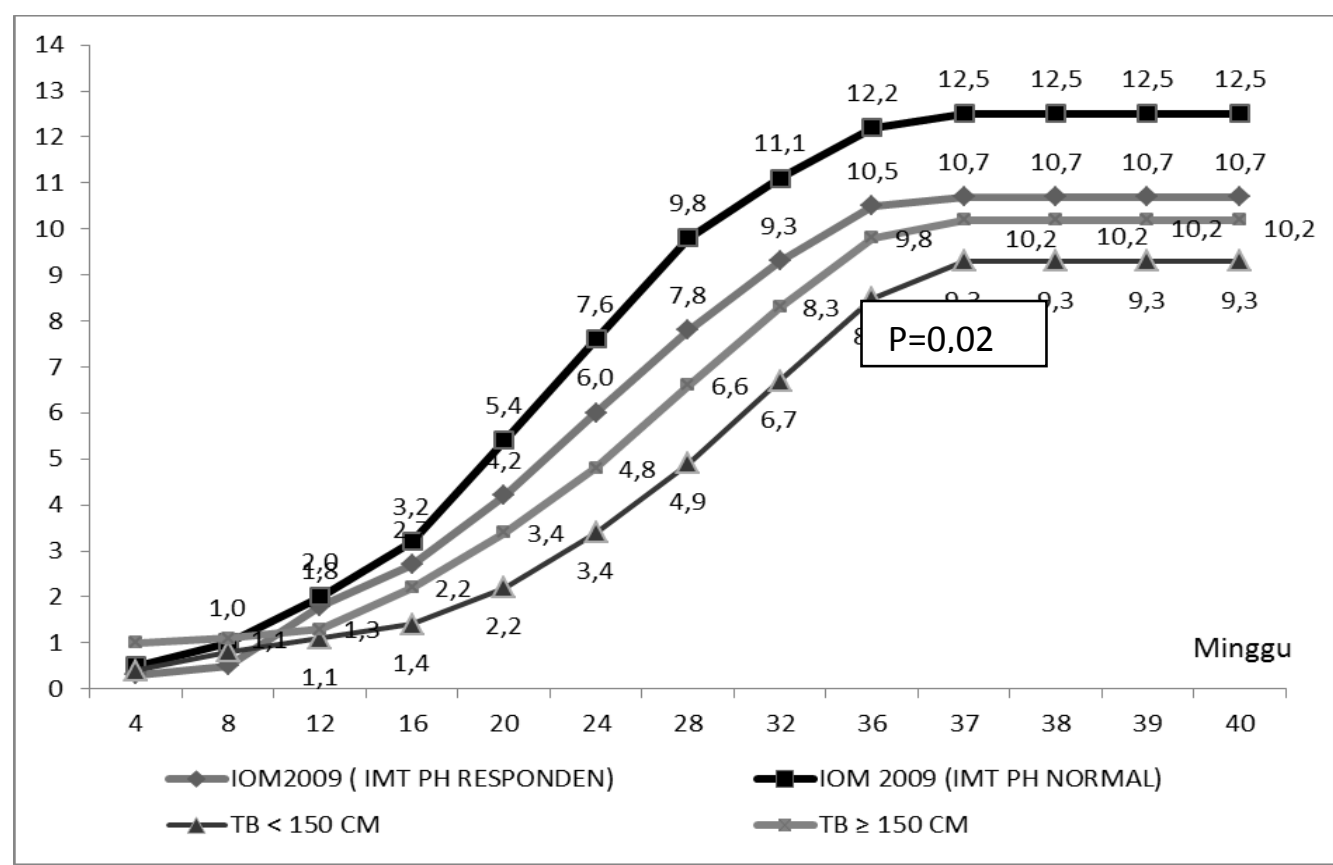

Gambar 1

Pertambahan berat badan ibu Menurut Tinggi badan di Kelurahan Kebon Kalapa, Ciwaringin, Babakan, Babakan Pasar dan Panaragan 
Pada Tabel 3 berikut terlihat bahwa umur responden sekitar 28 - 31 tahun, dan proporsi wanita dengan umur berisiko bila hamil sebesar $15-34$ persen. Berat badan wanita pra hamil sekitar $54-56 \mathrm{~kg}$ dan proporsi wanita pra hamil $<45 \mathrm{~kg}$ sebesar 15 - 19 persen. Rerata tinggi badan wanita pra hamil $151-152 \mathrm{~cm}$, dan proporsi wanita pra hamil dengan tinggi badan berisiko $(<150 \mathrm{~cm})$ adalah $38-41$ persen. Indeks massa tubuh (IMT) wanita pra hamil adalah $23-24 \mathrm{~kg} / \mathrm{m}^{2}$, dan proporsi wanita pra hamil dengan IMT berisiko terhadap kehamilan sebanyak 9 - 12 persen. Rerata lingkar lengan atas wanita pra hamil $27-28 \mathrm{~cm}$, dan yang berisiko kurang energi kronis sebanyak $10-16$ persen. Diantara data tersebut di atas, menunjukkan bahwa sekitar 10 sampai 41 persen wanita pra hamil dengan ukuran antropometri yang berisiko terhadap kehamilan.

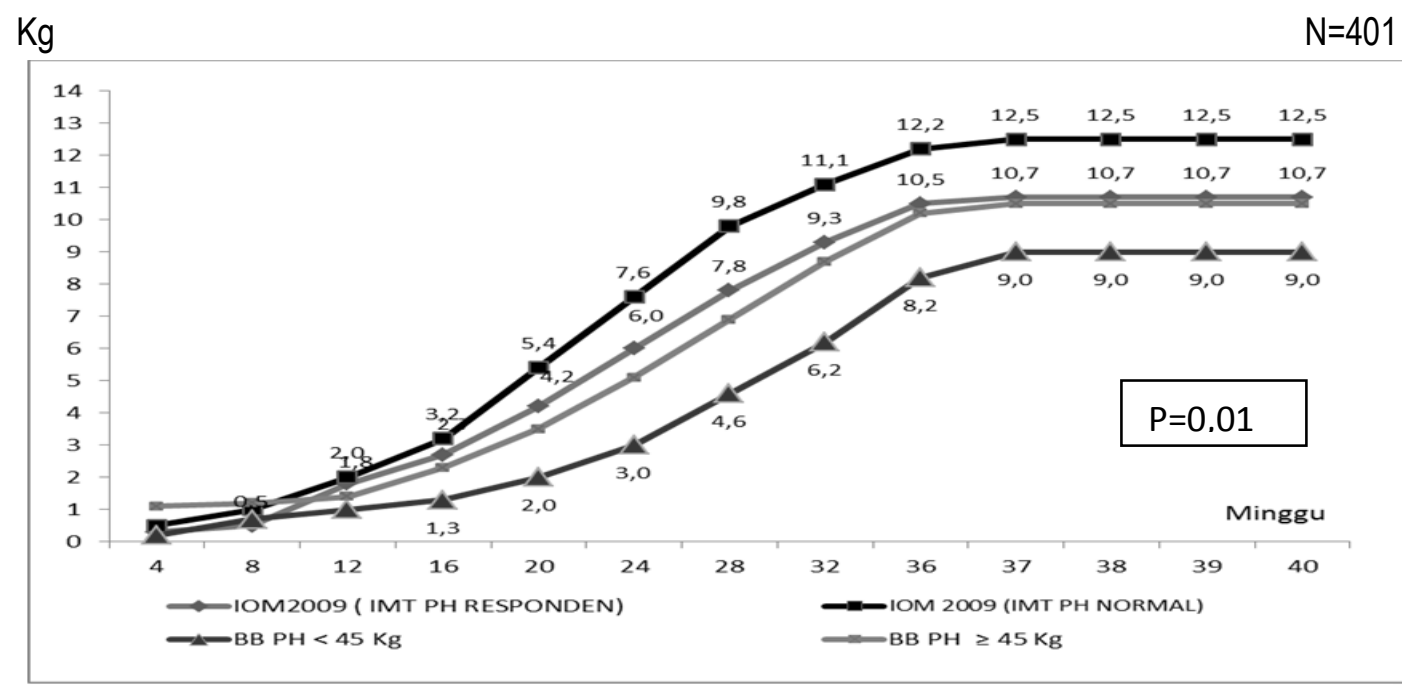

\section{Gambar 2}

Pertambahan Berat Badan Ibu Menurut Berat Badan Pra Hamil di Kelurahan Kebon Kalapa, Ciwaringin, Babakan, Babakan Pasar dan Panaragan

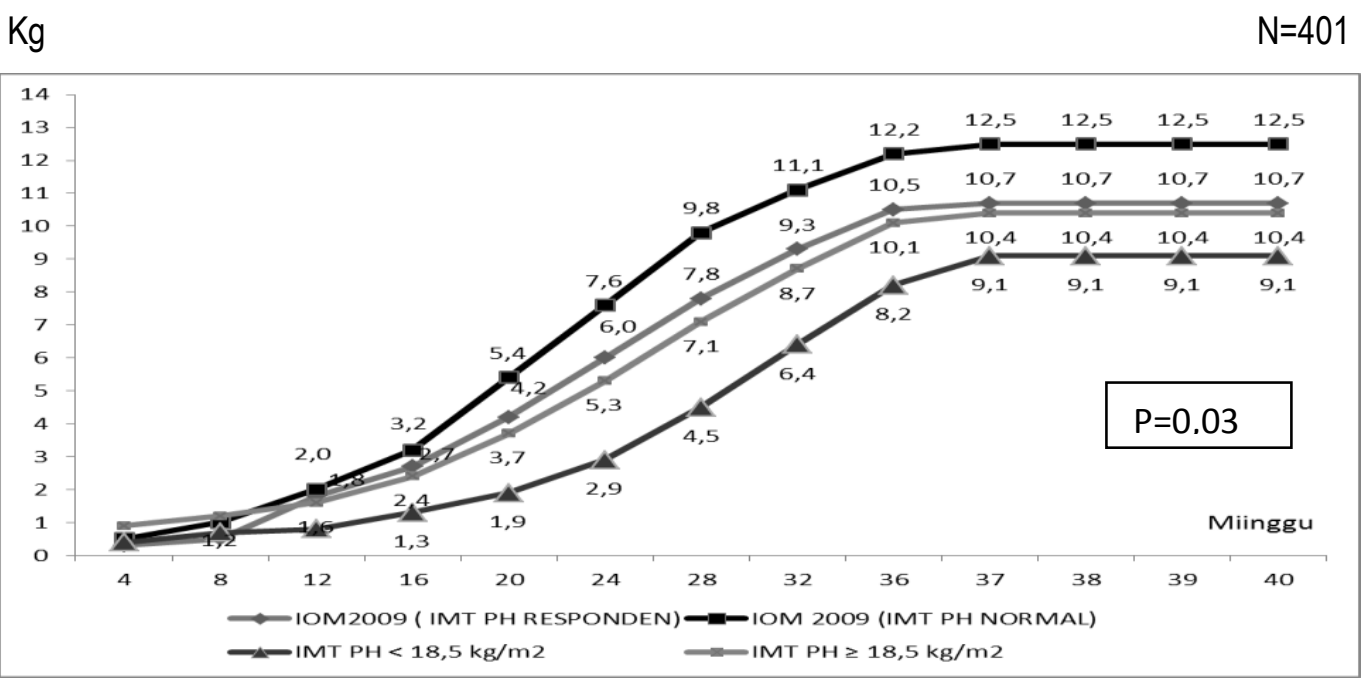

Gambar 3

Pertambahan berat badan selama hamil menurut Indeks Massa tubuh Ibu Pra Hamil di Kelurahan Kebon Kalapa, Ciwaringin, Babakan, Babakan Pasar dan Panaragan 


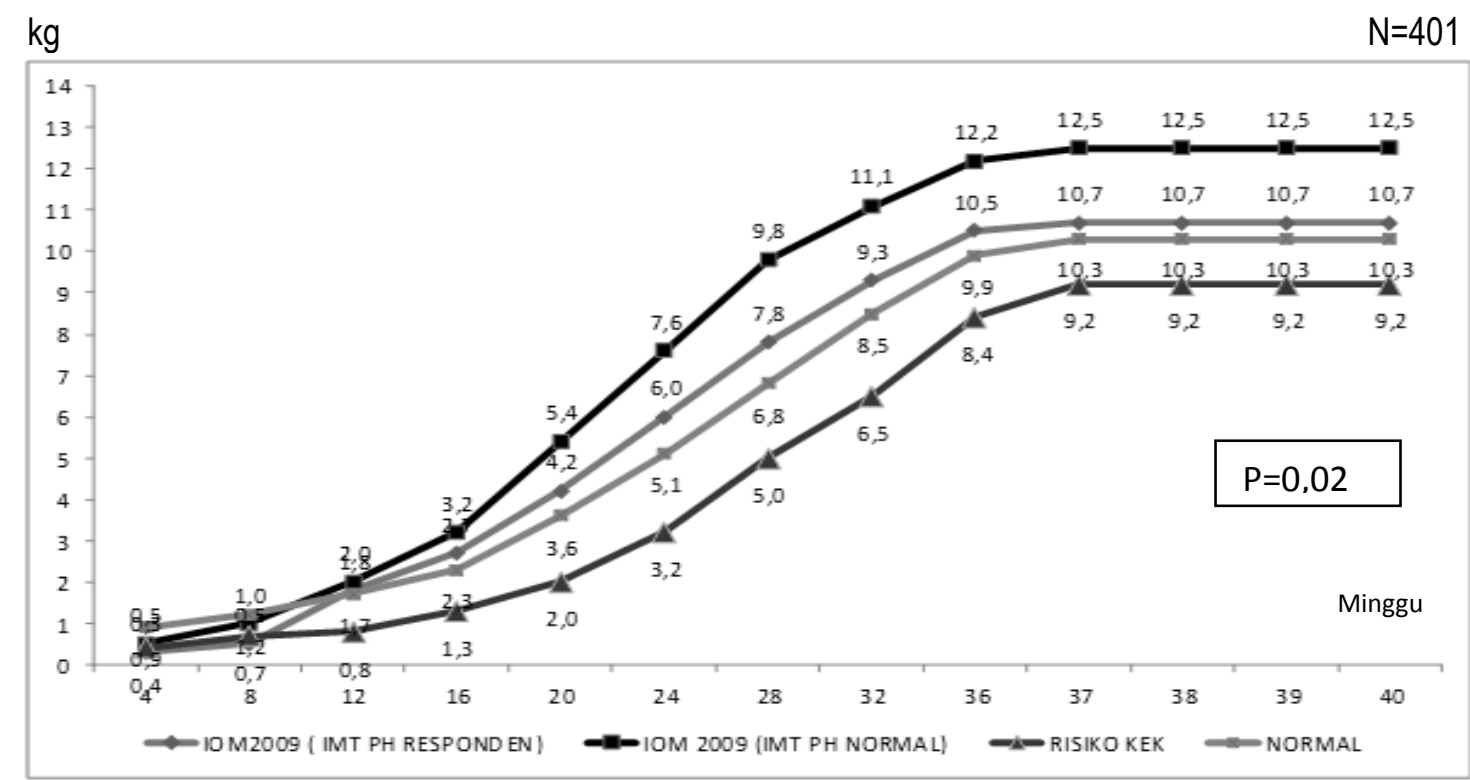

Gambar 4

Pertambahan Berat Badan Ibu Selama Hamil Menurut Risiko KEK di Kelurahan Kebon Kalapa, Ciwaringin, Babakan, Babakan Pasar dan Panaragan

\section{Pengaruh ukuran antropometri terhadap status gizi ibu hamil}

Pertambahan berat badan selama kehamilan responden penelitian ini dibawah rekomendasi11 IOM 2009 sebanyak $12,5 \mathrm{~kg}$ untuk wanita yang memulai kehamilan dengan IMT pra hamil normal $\left(\geq 18,5 \mathrm{~kg} / \mathrm{m}^{2}\right)$. Demikian juga bila dibandingkan rekomendasi IOM 2009 apabila mengacu pada IMT responden ketika pra hamil (rentang IMT responden ketika pra hamil adalah 9,3 - 42,4), pertambahan berat badan selama hamil seharusnya $10,7 \mathrm{~kg}$. Diantara 2400 wanita pra hamil, sekitar 401 wanita telah melahirkan. Pertambahan berat badan wanita selama kehamilan adalah $9,8 \mathrm{~kg}$ $(5,6 \mathrm{~kg})$ dan sebanyak 22,7 persen ibu hamil dengan pertambahan berat badan selama kehamilan < 9,8 kg, artinya seperempat responden dengan status gizi selama kehamilan kurang baik (data tidak disajikan dalam tabel). Pengaruh ukuran antropometri terhadap pertambahan berat berat badan selama kehamilan seperti disajikan sebagai berikut. Pertambahan berat badan ibu hamil dengan tinggi badan $<150 \mathrm{~cm}$ lebih rendah dari ibu dengan tinggi badan $\geq 150 \mathrm{~cm}$.

Pertambahan berat badan ibu selama kehamilan yang memulai kehamilan dengan tinggi badan $<150 \mathrm{~cm}$ lebih rendah dari ibu yang tinggi badannya $\geq 150 \mathrm{~cm}$. Rentang perbedaan mulai terjadi pada 12 minggu kehamilan (Gambar 1). Pertambahan berat badan selama kehamilan pada ibu yang memulai kehamilan dengan berat badan pra hamil < $45 \mathrm{~kg}$, lebih rendah dari ibu yang memulai kehamilan dengan berat badan pra hamil $\geq 45 \mathrm{~kg}$. Rentang perbedaan terjadi sejak awal kehamilan (Gambar 2). Data pada Gambar 3 menjelaskan bahwa pertambahan berat badan selama kehamilan pada ibu yang memulai kehamilan dengan IMT $<18,5 \mathrm{~kg} / \mathrm{m}^{2}$ atau ibu kurus, lebih rendah dari ibu yang memulai kehamilan dengan status gizi normal (IMT $\geq 18,5 \mathrm{~kg} / \mathrm{m}^{2}$ ). Pertambahan berat badan selama kehamilan pada ibu yang memulai kehamilan dengan ukuran LiLA $<23,5 \mathrm{~cm}$ (risiko KEK), lebih rendah dari ibu yang memulai kehamilan dengan ukuran LiLA normal (LiLA $\geq$ $23,5 \mathrm{~cm}$ ). Rentang perbedaan pertambahan berat badan selama kehamilan pada ibu yang memulai kehamilan dengan IMT $<18,5 \mathrm{~kg} / \mathrm{m}^{2}$, LiLA $<23,5 \mathrm{~cm}$ dan berat badan $<45 \mathrm{~kg}$ terjadi mulai awal kehamilan.

\section{BAHASAN}

Pada analisis ini batasan ukuran antropometri berisiko adalah untuk risiko kejadian penyakit tidak menular ketika dewasa ${ }^{1}$. Barker, 2008 menjelaskan teori fetal origin hypothesis bahwa janin yang mengalami keterbatasan zat gizi akan melakukan 
mekanisme coping untuk mempertahankan kelangsungan kehidupannya. Mekanisme coping dilakukan dengan perubahan metabolisme tubuh. Janin akan melakukan katabolisme terhadap substratnya sendiri untuk mengasilkan energi, yang akan memperlambat metabolisme tubuh dan menurunkan penggunaan substrat penghasil energi untuk menghemat energi yang dikeluarkan. Kondisi ini menyebabkan terjadinya fetal programming atau perubahan permanen pada struktur dan fungsi organ tubuh yang sedang berkembang ketika terjadi keterbatasan zat gizi.1,12

Keterlambatan pertumbuhan selama dalam kandungan berkaitan dengan peningkatan alokasi zat gizi pada jaringan lemak untuk mempercepat pertumbuhan anak. Ini mempunyai kontribusi pada peningkatan risiko kemunculan penyakit jantung koroner, hipertensi dan diabetes mellitus di masa mendatang. ${ }^{12}$

Pertambahan berat badan total selama kehamilan adalah selisih berat badan ibu pada akhir kehamilan dengan berat badan ibu sebelum hamil ${ }^{13,14}$, yang merupakan refleksi dari keseimbangan energi yang dikonsumsi (dari makanan) dengan energi yang dikeluarkan (metabolisme dan aktifitas) atau dikenal sebagai net positive energy balance. ${ }^{13,14}$ Oleh sebab itu pertambahan berat badan ibu selama kehamilan merupakan indikator terbaik untuk menentukan status gizi ibu hamil.

Berat badan lahir bayi dipengaruhi secara langsung oleh pertambahan berat badan ibu selama kehamilan. ${ }^{7,11} \mathrm{Di}$ sisi lain pertambahan pertambahan berat badan ibu selama kehamilan di pengaruhi IMT ibu sebelum hamil, dan tinggi badan ibu serta konsumsi energi dan zat gizi makro-mikro. 8,13

Pada penelitian yang dikaitkan dengan risiko penyakit kronis (tidak menular), tinggi badan berisiko untuk hamil adalah lebih rendah dari $150 \mathrm{~cm}^{8}$. Disisi lain, ibu hamil dengan risiko kehamilan tinggi bagi ibu dan bayi adalah bila Berat badan $<45 \mathrm{~kg}$, LiLA $<23,5 \mathrm{~cm}^{9,10}$ dan IMT ibu sebelum hamil. ${ }^{8}$

Pada penelitian ini terbukti bahwa dengan ukuran antropometri berisiko (berat badan sebelum hamil $<45 \mathrm{~kg}$, tinggi badan $<150 \mathrm{~cm}$, LiLA $<23,5 \mathrm{~cm}$, IMT sebelum hamil < 18,5 $\mathrm{kg} / \mathrm{m}^{2}$ ) pertambahan berat badan ibu lebih rendah dari rekomendasi IOM 2009 menurut IMT sebelum hamil $\left(\geq 18,5 \mathrm{~kg} / \mathrm{m}^{2}\right)^{11}$, maupun rerata IMT sebelum hamil responden penelitian ini $\left(24,2 \pm 4,7 \mathrm{~kg} / \mathrm{m}^{2}\right)$.

Risiko tinggi badan ibu terhadap kehamilan adalah kesulitan kehamilan akibat bentuk panggul sempit. Umumnya tinggi badan $<145$ $\mathrm{cm}$ berisiko lebih tinggi untuk mengalami kesulitan kehamilan. Risiko lainnya adalah ibu melahirkan bayi berat lahir rendah $<2500$ gram), sebab berkaitan dengan umur kehamilan yang lebih pendek, sehingga terjadi persalinan dini. Ibu dengan tinggi badan $<150 \mathrm{~cm}$ lebih besar kemungkinan melahirkan lebih dini. Ibu dengan tinggi badan $<150 \mathrm{~cm}$ menyebabkan volume aliran darah ke rahim lebih kecil, dan ini menyebabkan suplai gizi ke janin juga berkurang. 3,13

Berat badan ibu pra hamil berguna untuk penentuan prognosis serta keputusan perlu tidaknya dilakukan terapi gizi secara intensif. Status gizi buruk ditandai oleh berat sebelum hamil 10 persen di bawah atau 20 persen di atas berat ideal. Berat badan pra hamil kini diperlukan untuk menentukan pola pertambahan berat. ${ }^{13}$

LiLA $<23,5 \mathrm{~cm}$ berisiko mengalami kesulitan persalinan, melahirkan bayi dengan berat lahir rendah, perdarahan dan kematian pada ibu dan janin. ${ }^{15}$ Bukti empiris pada beberapa penelitian menjelaskan bahwa indeks massa tubuh pra hamil merupakan proksi yang sangat baik dalam menilai status gizi ibu pasca melahirkan dan bayi yang dilahirkan (outcome kehamilan), bila dibandingkan indikator tunggal (berat badan atau tinggi badan saja). ${ }^{7,10,16}$

Faktor lingkungan dan genetika berperan pada berat badan seseorang termasuk ibu hamil. Seseorang yang lebih tinggi memiliki lebih berat dibandingkan seseorang yang lebih pendek, sebab memerlukan makanan lebih banyak. Untuk itu IMT yang merupakan keseimbangan antara berat badan dan tinggi badan merupakan indikator yang lebih baik, karena berat badan seseorang di koreksi oleh tinggi badannya. Oleh sebab itu IMT ibu sebelum hamil untuk proksi outcome kehamilan yang baik.

Untuk pemantauan hasil kehamilan, apabila tinggi badan ibu tidak tersedia datanya karena keterbatasan alat ukur atau petugas ukur, maka penggunaan data berat badan dapat digunakan, sebab berat badan pra hamil terbukti berisiko pada hasil kehamilan. Demikian juga bila tidak tersedia data berat badan ibu sebelum hamil, 
dan yang tersedia hanya data tinggi badan, maka penggunaan data tinggi badan saja dapat digunakan untuk proksi hasil kehamilan.

Data ibu hamil berisiko kurang energi kronis harus di konfirmasi dengan pertambahan berat badan selama kehamilan, atau berat badan pada umur kehamilan tertentu yang kemudian di sesuaikan dengan anjuran. ${ }^{11}$

\section{SIMPULAN DAN SARAN}

\section{Simpulan}

Pertambahan berat badan ibu selama kehamilan lebih rendah secara bermakna pada ibu dengan ukuran antropometri berisiko (berat badan sebelum hamil $<45 \mathrm{~kg}$, tinggi badan $<$ $150 \mathrm{~cm}$, IMT sebelum hamil $<18,5 \mathrm{~kg} / \mathrm{m}^{2}$, LiLA $<23,5 \mathrm{~cm})$. Secara keseluruhan terdapat selisih sekitar 3,0 - 3,5 kg dari rekomendasi. Selisih terbesar adalah pada ibu dengan IMT sebelum hamil $<18,5 \mathrm{~kg} / \mathrm{m}^{2}$

\section{Saran}

Ibu yang memulai kehamilan dengan status gizi kurus (IMT $<18,5 \mathrm{~kg} / \mathrm{m}^{2}$ ) perlu pemantauan berkala lebih ketat agar pertambahan berat badan selama kehamilan sesuai anjuran dapat terpenuhi.

\section{UCAPAN TERIMA KASIH}

Kami mengucapkan terima kasih kepada pimpinan Badan Litbang Kesehatan, para peneliti dan enumerator kohor tumbuh kembang anak. Tanpa kerja sama yang sangat baik artikel ini tidak dapat kami susun.

\section{RUJUKAN}

1. Global Nutrition Report, 2014. Available from: http://www.globalnutritionreport.org/

2. Kementerian Kesehatan. 2013. Riset Kesehatan Dasar. Laporan. Jakarta: Badan Litbang Kesehatan, 2013.

3. WHO. 2014. 2025 nutrition targets policy briefs: stakeholders' input.m Available from: http://www.who.int/nutrition/targets_policybriefs input_2014/en/.

4. Nabaro, D. Scaling Up Nutrition. Makalah disampaikan pada Widya Karya Nasional Pangan dan Gizi ke X. Jakarta: LIPI, 2012.
5. Achadi EL. Seribu hari yang menentukan masa depan bangsa. Pidato Upacara Pengukuhan Guru Besar tetap dalam Bidang IImu Gizi Masyarakat. Fakultas Kesehatan Masyarakat Universitas Indonesia. Jakarta, 4 Januari 2014.

6. Neggers Y, Goldenberg, RL. Some Thoughts on Body Mass Index, Micronutrient Intakes and Pregnancy Outcome. J. Nutr. 2003;133:1737S40S

7. Bisai S. Maternal Height As An Independent Risk Factor For Neonatal Size Among Adolescent Bengalees In Kolkata, India. Ethiop J Health Sci. 2010;.20(3):153-158

8. Mavalankar DV, Trivedi CC, Gray RH. Maternal weight, height and risk of poor pregnancy outcome in Ahmedabad, India. Indian Pediatrics 1994; 31(10): 1205-1212.

9. Tang AM, Dong K, Deitchler M, Chung M , Manasseh ZM, Tumilowicz A, Wanke S. Use of Cutoffs for Mid-Upper Arm Circumference (MUAC) as an Indicator or Predictor of Nutritional and HealthRelated Outcomes in Adolescents and Adults: A Systematic Review . Washington: USAID - FANTA III, 2013. b

10. Krasovec, K. Arm circumference: background issues. In: Krasovec, K.\& Anderson, M. A. ed. Maternal nutrition and pregnancy outcomes. Washington, DC: Pan American Organization, 1991; p.119-31

11. Institute of Medicine. Nutrition during pregnancy. Washington DC: National Academy Press. 2009.

12. Gluckman PD, Hanson MA, Bateson $P$, Beedle AS, Law CM, Bhutta ZA et al. Towards a New Developmental Synthesis: Adaptive Developmental Plasticity and Human Disease. Lancet 2009; 373:1654-1657.

13. Institute of Medicine. Nutrition During Pregnancy: Part I: Weight Gain, Part II: Nutrient Supplements. Washington, D.C.: National Academy Press, 1990.

14. Brown, Judith E. Nutrition through the life cycle $2^{\text {nd }}$ edition. London: Belmont Thomson Wadsworth, 2005

15. Kementerian Kesehatan. Pedoman Gizi lbu Hamil Risiko Kurang Energi Kronis (KEK). Jakarta: Direktorat Bina Gizi, 2014.

16. Achadi, E L, Irawati A. How Reliable are Weight at Trimester I and "Estimated" PrePregnancy Weight in Predicting Pre-Pregnancy Weight? Jurnal Gizi Jurnal Nutrire Diaita 2008;1(2):163-171. 
